\title{
Public health: who, what, and why?
}

\author{
Jason L. Cabaj ${ }^{1,2,3}$ (D) Richard Musto ${ }^{1,2} \cdot$ William A. Ghali ${ }^{1,2,4}$
}

Received: 20 June 2018 / Accepted: 20 March 2019 / Published online: 12 April 2019

(C) The Canadian Public Health Association 2019

\begin{abstract}
There has been renewed concern about the state of public health in Canada, with several recent articles in this journal suggesting that the discipline of public health is under threat and that there has been a significant erosion of its core infrastructure. We strongly agree with the need for a well-resourced formal public health system and preservation of capacity to carry out core public health functions, while also positing a complementary narrative that emphasizes the possibility for a broad notion of public health to persevere and thrive in the face of these challenges. We consider what public health is, who public health is, and why public health exists, and suggest that the answers to these questions point to opportunities to strengthen the necessary interdisciplinary approaches that can best address current and future public health concerns.
\end{abstract}

\section{Résumé}

L'état de la santé publique au Canada suscite des préoccupations renouvelées; plusieurs articles publiés récemment dans cette revue indiquent que la discipline de la santé publique est. menacée, et que son infrastructure de base subit une érosion importante. Nous convenons tout à fait de la nécessité d'avoir un système de santé publique officiel doté de ressources suffisantes et de préserver la capacité d'exercer les fonctions essentielles de la santé publique, mais nous avançons aussi un discours complémentaire qui insiste sur la possibilité d'une notion élargie de la santé publique pour persévérer et prospérer malgré les difficultés. Nous examinons en quoi consiste la santé publique, qui en sont les acteurs et pourquoi elle existe, et nous faisons valoir que les réponses à ces questions suggèrent des possibilités de renforcer les démarches interdisciplinaires nécessaires les mieux à même d'aborder les préoccupations actuelles et futures en santé publique.

Keywords Public health $\cdot$ Health in all policies $\cdot$ Advocacy

Mots-clés Santé publique $\cdot$ La santé dans toutes les politiques $\cdot$ Défense des droits

Several recent articles in this journal have suggested that the discipline of public health is under siege (Potvin 2014) and that there has been a significant erosion of its core infrastructure (Hancock 2018). These are concerning messages in a

Jason L. Cabaj

jlcabaj@ucalgary.ca

1 Department of Community Health Sciences, Cumming School of Medicine, University of Calgary, Calgary, Alberta, Canada

2 O'Brien Institute for Public Health, Cumming School of Medicine, University of Calgary, Calgary, Alberta, Canada

3 Population Public \& Indigenous Health, Alberta Health Services, Calgary, Alberta, Canada

4 Department of Medicine, Cumming School of Medicine, University of Calgary, Calgary, Alberta, Canada vulnerable time. Public health programs and services have often been considered a soft target for budget cuts, partially because some public health goals are perceived to be valueladen and partisan. It is often only when public health emergencies such as Walkerton and SARS occur that public awareness of, and political commitment for, prevention activities and public health increases (O'Connor 2002; Naylor n.d.).

The dialogue surrounding these challenges has also brought forth some proposed mitigating strategies and solutions. Guyon and colleagues (Ak'ingabe et al. 2017), also in this journal, provide a number of recommendations for societal action to address the weakening of public health and critical challenges to the discipline. These include formalizing and elevating the status of public health in health authorities and governments, affirming the independence of Medical Officers of Health, and adequately resourcing a strong and resilient Canadian public health system. Ultimately, these 
recommendations underline the importance of the core public health functions and essential services, and the need to maintain a motivated, skilled, and well-resourced public health workforce.

In this commentary, we second these concerns and calls for action, while also positing a complementary narrative focusing on how public health can persevere and thrive in the context of these trends. In considering what public health is, who public health is, and why public health matters, we suggest that the answers to these questions identify an increasingly interdisciplinary domain that must continually evolve to effectively address current and future public health concerns.

\section{WHAT is public health?}

Similar to the challenges associated with comprehensively defining health itself, the development of a general and uncontentious definition for public health has proven elusive, with a variety of approaches emphasizing different aspects of public health. Acheson's influential definition from 1988 asserts that public health is 'the science and art of preventing disease, prolonging life and promoting human health through organized efforts and informed choices of society, organizations, public and private, communities and individuals' (Acheson 1988); it effectively captures that public health is concerned with the health of populations, has a future orientation, and requires societal/collective action often involving coordination across different sectors. The scope of public health in this broad sense encompasses all organized societal efforts that seek to establish, maintain, and improve health. This implies the inclusion of all activities that promote health, prevent, mitigate and treat disease, and take action on the social and ecological determinants of health, often requiring public policy change and community action.

Through a health in all policies lens, public health is everywhere and is everything. The challenge, however, with definitions encompassing all factors that affect population health is the risk of a loss of focus and dilution of what public health really is at its core. Conversely, narrow definitions, based solely on activities of the public health workforce or societal efforts to address discrete issues, risk underestimating the impact of upstream action on the systemic factors that create conditions for health. This tension of both needing to retain disciplinary identity (in relation to the public health workforce and services) while also capturing plurality and breadth (considering population health more broadly) is well captured in John Last's description of public health as 'a way of thinking, a set of disciplines, an institution of society, and a manner of practice...with an increasing number and variety of specialized domains and demands of its practitioners an increasing array of skills and expertise' (Last 2007).

\section{WHO is public health?}

This leads to consideration of the who in public health, and the challenge for public health practitioners, however organized, to engage all relevant sectors who share public health goals (or their co-benefits) while being respectful of each group's contributions and perspectives (i.e., avoiding health imperialism). John Snow, the physician who investigated a London cholera outbreak in 1854, epitomizes both the enigma of this question and the tremendous opportunity that resides in its answer. Described as a father to public health, epidemiology, anaesthesia, and health geography, Snow adopted a number of different disciplinary paradigms and problem-solving approaches in his singular work solving a public health crisis (Oleckno 2008). Contemporary public health nearly always requires an interdisciplinary team-based approach, and with capacity and fragmentation issues challenging the traditional public health workforce, contributions of other health and non-health professionals are becoming increasingly important. In particular, there is a key role for academia in generating and translating evidence in collaboration with the multiple actors who influence health and health equity-determining policies (Kershaw 2018). Alberta's Strategic Clinical Networks (SCNs) are one example of an attempt to facilitate this process by providing a platform for innovation and rapid mobilization of knowledge to inform practice and policy.

As former CDC Director Thomas Frieden points out in his influential 'The Future of Public Health' article, all health care shares the goal of maximizing health gains (Frieden 2015). In the context of regionalization, which has challenged public health in many Canadian jurisdictions, there is a continued need for collective leadership to reorient health authorities to more fully embrace a population health mandate (Marchildon 2017). In several provinces, attempts have been made to engage primary care physicians through mechanisms such as Primary Care Networks, which provide incentives to family physicians to improve chronic disease management and adopt a population health approach. Rachlis (Rachlis 2004) has also identified several examples of effective collaboration between public health and acute care facilitated by regionalized systems, including more effective response to influenza outbreaks, healthy and supportive earlier discharge of mothers and babies postpartum, and introduction of harm reduction activities. Although hopeful perspectives must be tempered by the modest nature of successes to date and acknowledgement of the time required for fundamental shifts in attitudes and roles, there should be optimism that health authorities are starting to adopt healthy communities/cities approaches and are including intersectoral collaboration centrally in their strategic planning.

Twenty-first century challenges will also require further leveraging of the strengths of civil society, and in some cases, the private sector as well. Innovations in domains ranging 
from health and healthcare technologies, to vaccine and drug development, to transportation and energy, and many others will be necessary to achieve public health goals that cannot be addressed by the work of classic public health professions alone. This broader notion of public health must by necessity invoke a big tent, with multiple disciplines, perspectives, and agendas, that when aligned have great potential. Indeed, interdisciplinary and cross-sectoral initiatives have produced some of humankind's notable public health wins, such as the control of infectious diseases, reductions in transportation-related injuries and deaths, tobacco control gains, and several other great achievements of public health (Centers for Disease Control and Prevention (CDC) 1999).

\section{And last, WHY public health?}

Canada's first Chief Public Health Officer, Dr. David ButlerJones, called the health of the public 'the foundation of prosperity' (Butler-Jones 2007). Several raison d'êtres for public health support this claim. There are of course the high-profile public health emergencies like global pandemics that call for a robust public health workforce. Notably, the Public Health Agency of Canada was born from one such emergency, the aforementioned SARS outbreak. It remains to be seen whether a similar analysis and call for change will come on the heels of the opioid crisis. Significant efforts have also been directed toward providing compelling evidence for decision makers to highlight the positive (and often cost-saving) return on investment of public health interventions, and demonstrating that disinvestment in prevention often leads to increases in downstream health service use and costs (Masters et al. 2017).

The final compelling reason for a thriving public health enterprise is that health (and illness) can be found in all policies. Social spending decisions have the potential to impact health most profoundly (Dutton et al. 2018), and there are innumerable policy actors who influence the distribution of health determinants and conditions for health. Globally, the comprehensive action required to address the health, social, and environmental threats we face- such as rising inequality, increasing threat of climate change, and the numerous challenges targeted by the Sustainable Development Goalsrequires transformative societal change (Whitmee et al. 2015). It is therefore both the responsibility and great opportunity for public health, and especially those with a formal mandate, to advance a health-in-all-policies agenda by leveraging traditional roles and expertise to provide supportive infrastructure for collective efforts to improve population health, often through creative new partnerships and coalitions. To facilitate this collaborative work, further competency development is needed in domains such as leadership, advocacy, and community engagement.
In closing, we emphasize that this commentary is not a rebuttal or an argument against claims that public health systems are under siege, eroding, or weakening. There are many forces that challenge public health. We believe, however, that there is another narrative that provides an important complementary point of view. By many measures, human health at the population level is better today than ever before, and public health's role in this progress should be recognized (Rosling et al. 2018). These gains have been made through contributions of an increasingly broad and diverse workforce that spans multiple disciplines and sectors. To address the immense challenges we face, public health can, and must, continue to thrive through increasingly collective and collaborative efforts to improve health and well-being.

\section{Compliance with ethical standards}

Conflict of interest The authors declare that they have no conflict of interest

\section{References}

Acheson, E. D. (1988). On the state of the public health [the fourth Duncan lecture]. Public Health, 102(5), 431-437.

Ak'ingabe, G., Hancock, T., Kirk, M., et al. (2017). The weakening of public health: a threat to population health and health care system sustainability. Canadian Journal of Public Health, 108(1), e1-e6.

Butler-Jones, D. (2007). The health of the public is the foundation of prosperity: the work of the Public Health Agency of Canada at home and around the world. CMAJ, 177(9), 1063-1064.

Centers for Disease Control and Prevention (CDC). (1999). Ten great public health achievements-United States, 1900-1999. MMWR. Morbidity and Mortality Weekly Report, 48(12), 241-243.

Dutton, D. J., Forest, P.-G., Kneebone, R. D., et al. (2018). Effect of provincial spending on social services and health care on health outcomes in Canada: an observational longitudinal study. CMAJ, 190(3), E66-E71.

Frieden, T. R. (2015). SHATTUCK LECTURE: the future of public health. The New England Journal of Medicine, 373(18), 1748-1754.

Hancock, T. (2018). Erosion of public health capacity should be a matter of concern for all Canadians. Canadian Journal of Public Health, 108(5-6), e458-e461.

Kershaw, P. (2018). The need for health in all policies in Canada. Canadian Medical Association Journal, 190(3), E64-E65.

Last, J. M. (2007). A dictionary of public health. USA: Oxford University Press.

Marchildon, G. P. (2017). Physicians and regionalization in Canada: past, present and future. Canadian Medical Association Journal, 189(36), E1147-E1149.

Masters, R., Anwar, E., Collins, B., et al. (2017). Return on investment of public health interventions: a systematic review. Journal of Epidemiology and Community Health, 71(8), 827-834.

Naylor, D. Learning from Sars: renewal of public health in Canada (p. 2003234). Health Canada Report No.: 0662349849.

O'Connor, D. R. (2002). Report of the Walkerton inquiry: the events of May 2000 and related issues: a summary. Ontario Ministry of the Attorney General. 
Oleckno, W. A. (2008). Remembering Dr. John Snow on the sesquicentennial of his death. Canadian Medical Association Journal, 178(13), 1691-1692.

Potvin, L. (2014). Canadian public health under siege. Canadian Journal of Public Health, 105(6), e401-e403.

Rachlis, M. (2004). Prescription for excellence. tc., 2003, 900501900501.

Rosling, H., Rönnlund, A. R., \& Rosling, O. (2018). Factfulness: ten reasons we're wrong about the world-and why things are better than you think. Flatiron Books.
Whitmee, S., Haines, A., Beyrer, C., et al. (2015). Safeguarding human health in the Anthropocene epoch: report of The Rockefeller Foundation-Lancet Commission on planetary health. Lancet, 386(10007), 1973-2028.

Publisher's note Springer Nature remains neutral with regard to jurisdictional claims in published maps and institutional affiliations. 